\title{
РАЗВИТИЕ ПРЕДПРИНИМАТЕЛЬСТВА В ЭКОНОМИКЕ СОВРЕМЕННОЙ РОССИИ
}

\author{
(c) 2019 Коновалова Мария Евгеньевна \\ доктор экономических наук, зав. кафедрой экономической теории \\ Самарский государственный экономический университет, Россия, Самара \\ E-mail:mkonoval@mail.ru \\ (c) 2019 Кузьмина Ольга Юрьевна \\ кандидат экономических наук, доцент кафедры экономической теории \\ Самарский государственный экономический университет, Россия, Самара \\ E-mail: pisakina83@yandex.ru \\ (ㄷ) 2019 Медведева Татьяна Юрьевн \\ студент \\ Самарский государственный экономический университет, Россия, Самара
}

В статье рассматриваются основные проблемы внешней и внутренней среды предпринимательской деятельности в России, влияющие на развитие предпринимательской активности. Констатируется, что факторами, тормозящими развитие предпринимательской инициативы в России, являются высокая доля госсектора экономики, завышенная налоговая нагрузка, неблагоприятный инвестиционный климат, отсутствие работоспособной системы комплексного сопровождения начинающих предпринимателей, недостаточная информационная, психологическая и научная поддержка субъектов предпринимательской деятельности, несовершенство и противоречивость правовых актов, несбалансированная и коррупционно обусловленная работа контролирующих и инспектирующих органов.

Ключевые слова: предпринимательство, бизнес, государственное регулирование, экономика России.

Развитие инновационной экономики России, формирование сбалансированного рынка, проведение цифровых трансформаций и технологического насыщения производства невозможны без предпринимательской деятельности, наличие, функционирование и усиление которой составляют основу конкуренции, открытости экономики, модернизации и динамики повышения эффективности экономики.

Под предпринимательством понимается специальная, самостоятельная, инициативная, продуктивная и рисковая деятельность от своего имени и под свою ответственность для получения прибыли и саморазвития выбранной сферы. При сравнении понятий бизнес и предпринимательство [1] некоторые ученые отмечают в том что бизнес- это масштабная, крупная деятельность, а предприниматели - это малый и средний уровень функционирования, но многие сходятся в том, что их общей целью является получение прибыли. В основном различие связано с тем, что англоамериканское слово «бизнес» (business - в пер. с англ. деловой) включает также понятия дело, фирма, компания. Русское слово «предпринимательство» по своему содержанию опирается на выбор средств и приемов, попытка предпринимать усилия по осуществлению деятельности, выполнению неких работ. С экономической позиции нет смысла различать эти понятия, но с позиции адресности и масштабов все-таки предпринимательство больше понятно соотечественникам, демонстрируя определенную, если не полную, самостоятельность и свободу реализации личного и профессионального потенциала.

Теоретико-методологическую базу статьи составили работы таких современных российских исследователей, как Агеева О.А., Девянина А.В., Валеев Т.А., Калинина К.М., Костенко Р.В., Мурадян Л.З., Латышенко Е.П., Масленникова А.Ю., Попова И.Н., Мусаева П.С., Алимирзоева М.Г., Поляков Д.М., Посохова А.В., Слезко Л.В. и др. Обобщая изложенные в научных работах ученых определения, можно констатировать, что в условиях развития цифровой инновационноориентированной экономики [4] под предпринимательской деятельностью понимается ее организация в рамках компетенций самого 
предпринимателя, что позволяет получить по возможности максимальную прибыль, но только при условии создания востребованных обществом высоко технологических товаров и услуг с применением инновационных технологий [5]. Решая проблемы свободной самореализации, экономического развития и получения доходов, предприниматель вынужден думать об интересах потребителей своей продукции и услуг, так как на рынке бизнес зависит от того, купят у него или нет товар. Предпринимательство способствует согласованию интересов человека и общества, их «соизмеримости», во многом решает проблему занятости, социальной адаптивности [3]. Предприниматели являются активными участниками строительства гражданского общества, играют важную роль в реформировании российского общества, в формировании новых социальных отношений, распространяют в общественном сознании ценности новой капиталистической общественной системы, свободы мышления и социально-политической активности. Таким образом, социально ориентированная, коммерческая и новаторская деятельность предпринимательства не ограничивается экономической сферой, а ведет к преобразованию всей системы социально-экономических, информационных и коммуникационных отношений.

За почти тридцатилетний период с 1990 года по настоящее время в ускоренном режиме формировались рыночные отношения с ориентацией на достижения мирового рынка. Но за эти 25 лет на макро- и микроуровнях остро ощущалась, хотя и не всегда признавалась, специфика и проблемы резкого поворота от одной системы к другой, от социальных гарантий и государственной защиты до самостоятельной работы и рискованности. Сложности касаются и предпринимательства как по скорости вовлечения в социальноэкономические и процессы, так и по качеству формируемых целей, отношений, применяемых инструментов и собственности. В традициях и устоявшихся привычках для российских предпринимателей даже при стремлении к экономической свободе и независимости в принятии решений сложно отойти от постоянной оглядки на государственные органы, боязни этой зависимости и сдерживания рисков, определенной апатии в силу политической нестабильности и налогового давления, краткосрочности принимаемых действий и отсутствия стратегической перспективы в развитии. Какие бы цели не были поставлены Президентом и Правительством РФ пока не сформирована среда предпринимательства, нет последовательной и устоявшейся социальной атмосферы, благоприятной для самореализации каждого человека, пожелавшего стать предпринимателем. Останавливаясь исключительно на психологических особенностях ведения бизнеса, укажем, что, по сути, сущность предпринимательства можно определить, как ориентированность на инновации, поиск и изучение новых возможностей - таким образом, это в первую очередь характеристика поведения, а не вид деятельности. В этой связи для государства может быть целесообразно изыскание вариантов по запуску национальных проектов, способных оптимизировать поведенческие характеристики россиян. Актуальным для государства является вопрос формирования предпринимательского сознания, инициативности и предприимчивости в российском обществе, чему во многом должно способствовать эффективное проведение административной реформы, снижающей коррумпированность властных структур, а значит и изменяющей восприятие гражданами существующей в России социальноэкономической системы как исключительно несправедливой и лишенной социальных лифтов.

Дополнительно напомним о довлеющем и широко распространяемом утверждении, что предпринимателем может стать только 5-10\% населения, что это особый дар, особое мышление и мировоззрение. Так, по оценкам Посоховой А.В. неконкурентоспособность значительного числа российских малых предпринимателей заключается в «экстрапунитивном реагировании», ведущем к завышенной самооценке личных бизнес-перспектив: большинство причин своей низкой конкурентоспособности подобные предприниматели видят в действии экзогенных негативных факторов, абсолютно отрицая субъективную причинность их недостаточной конкурентоустойчивости [8]. При этом в противоположность утверждению о способности лишь малой доли населения к ведению эффективного бизнеса, массово создаются и активно рекламируются всевозможные курсы по личной инициативе, бизнес-развитию и прочему процветанию. Наверное, все же правда и суть сконцентрированы где-то по-середине: для того, чтобы стать предпринимателем надо все-таки предпринимать эти усилия, пробовать себя, активно и обоснованно действовать, иметь знания, учиться в процессе работы и верить в свои силы. Конечно, 
если иметь определенные предпосылки, базовые стартовые условия, то бизнес пойдет динамично в особенности с опорой на сложившуюся команду единомышленников. Но бывают и герои - одиночки, которые добиваются многого в силу уникальности своей идеи и своего настроя на победу.

Подчеркнем, что именно малое и среднее предпринимательство занимает важную, перспективную и специфическую часть хозяйственной структуры как на мировом, так и на региональном уровне современной экономической системы [6]. Значительная представленность малого предпринимательства, с одной стороны, повышает гибкость и адаптивность мировой глобальной системы, с другой - способствует укреплению стабильности, создавая рабочие места и динамично подстраиваясь под спрос покупателей. Малое и среднее предпринимательство во многих странах стало своеобразным катализатором промышленного развития, экспорта и, особенно, занятости [2]. Особо подчеркнем инновационную функцию малого предпринимательства: именно малые предприятия, стартапы являются основным создателем нововведений и генератором инновационных проектов. Однако важно учитывать, что при использовании малыми предприятиями в своей деятельности цифровых технологий резко возрастает предпринимательский риск. И это связано не только с выпуском новой высоко технологической продукции, но и с увеличением масштабов финансирования этого процесса, с открытостью системы отношений.

Рассматривая современное состояние малого предпринимательства в России, отметим, что по состоянию на 10 апреля 2019 г. в Едином реестре субъектов малого и среднего предпринимательства (МСП) было зарегистрировано 6141283 субъектов малого и среднего бизнеса с численностью занятых около 15781512 человек (таблица 1).

Мы выделили основные недостатки предпринимательской среды и ограничения, возникающие на пути развития малого предпринимательства в России:

1. Препятствия на пути получения и использовании финансовых ресурсов, отсутствие «длинных» кредитов, высокие кредитные ставки и требования к заемщику; налоговый прессинг; проблемные источники инвестирования, получения субсидий и грантов. И хотя программы льготного кредитования МСП наряду с сохранением ключевой ставки Банком России на уровне 7,75\% годовых достаточно позитивно влияют на условия кредитования, в целом ставки остаются на демотивирующе высоком уроне [9].

2. Малоэффективная образовательная и информационно-консультационная поддержка, отсутствие системы с четкой и понятной интерпретацией информации, отмечаемая населением и бизнес-сообществом даже несмотря на запуск АО «Корпорацией «МСП» обучающих программ «Азбука предпринимателя» и «Школа предпринимательства», а также Портала бизнеснавигатора МСП (smbn.ru), охватывающего 171 российский город с населением более 100 тысяч человек.

3. Отсутствие стимулирования к инновационной деятельности: индекс новизны, иллюстрирующий использование предпринимателями новых и новейших технологий, в России составляет $5,4 \%$, что в 4 раза ниже, чем показатели стран БРИКС и в 7 раз ниже, чем в США [7].

Таблица 1. Состав и структура малого бизнеса в России (по состоянию на 10.04.2019) [10]

\begin{tabular}{|c|c|c|c|c|c|c|c|}
\hline \multirow{3}{*}{ Территория регистрации } & \multirow{3}{*}{ Всего } & \multicolumn{6}{|c|}{ Из них } \\
\hline & & \multicolumn{3}{|c|}{ Юридических лиц } & \multicolumn{3}{|c|}{$\begin{array}{c}\text { Индивидуальных } \\
\text { предпринимателей }\end{array}$} \\
\hline & & микро & малые & средние & микро & малые & средние \\
\hline $\mathrm{P} \Phi$ & 6141283 & 2516093 & 221064 & 18340 & 3358450 & 27021 & 315 \\
\hline Центральный ФО & 1909919 & 889043 & 80014 & 7246 & 927357 & 6180 & 79 \\
\hline Северо-Западный ФО & 722901 & 352536 & 28739 & 2194 & 337068 & 2337 & 27 \\
\hline Южный ФО & 715798 & 190435 & 17084 & 1401 & 503382 & 3470 & 26 \\
\hline Северо-Кавказский ФО & 203838 & 44392 & 4300 & 428 & 153905 & 804 & 9 \\
\hline Приволжский ФО & 1094853 & 433512 & 40778 & 3223 & 611018 & 6248 & 74 \\
\hline Уральский ФО & 525480 & 215860 & 17984 & 1435 & 287511 & 2657 & 33 \\
\hline Сибирский ФО & 649796 & 271671 & 22185 & 1730 & 350921 & 3251 & 38 \\
\hline Дальневосточный ФО & 318698 & 118644 & 9980 & 683 & 187288 & 2074 & 29 \\
\hline
\end{tabular}


4. Коррупционные и бюрократические барьеры, нестабильность законодательной базы, высокая монополизированность рынка, недостаточная защищенность частной собственности. Так, например, выступая на заседании Госсовета России в апреле 2018 года Президент России Путин В.В. рассказал о желании регионов «порадеть своим фирмёшкам», в результате чего малоэффективные компании с государственным участием монополизируют рынки и занимают те ниши, где мог бы работать малый и средний бизнес, идет процесс картелизации конкурентных сфер экономики, снижается экономическая эффективность, подрывается предпринимательская инициатива [11].

Отталкиваясь от высказывания Президента России, мы бы хотели отдельно остановиться на негативном влиянии значительного по объему государственного сектора на уровень конкуренции в экономике и, соответственно, предпринимательскую активность в России. Поскольку само определение государственного сектора является нечетким и многопозиционным, эксперты и государственные деятели расходятся в оценках доли госсектора в современной экономике РФ. Однако по оценкам экспертов Федеральной антимонопольной службы (ФАС), с 2005 по 2015 год вклад государства и госкомпаний в ВВП России вырос с 35 до 70\% [12]. Данные показатели свидетельствуют о нарастании процессов огосударствления экономики и создания государственно-монополистического капитализма, сращивание бизнеса и власти; при этом с введением западных экономических санкций доля государства в экономике России лишь уси- лилась. Согласно данным ФАС России, по состоянию на 1 января 2018 года количество унитарных предприятий составило 18624, что на 39\% превосходит аналогичный показатель 2013 года [13]. Значительная доля унитарных предприятий функционирует в сферах водоснабжения, управления жилым фондом, торговли и оказания услуг. Участие унитарных предприятий в хозяйственной деятельности оказывает наиболее негативное влияние на конкуренцию на локальных рынках и влечёт их монополизацию. Более того, унитарные предприятия зачастую убыточны, т.к. если они покажут прибыль, то финансирование из государственного бюджета они не получат. Таким образом, для них отсутствует стимул быть эффективными. Данные предпосылки обусловили разработку ФАС законопроекта о реорганизации государственных и муниципальных предприятий [14], проходящего публичные обсуждения на различных площадках (так, в декабре 2018 года он был принят в I чтении Государственной Думы РФ [15]). Согласно законопроекту, государственные и муниципальные унитарные предприятия будут подлежать ликвидации или реорганизации по решению учредителя в срок до 1 января 2021 года (за исключением случаев создания унитарных предприятий для реализации функции национальной обороны или для работы в сферах естественных монополий).

Исходя из выделенных нами проблем развития предпринимательства, и в частности - малого и среднего бизнеса, целесообразно выделит следующие направления его поддержки (таблица 2).

\section{Таблица 2. Основные направления поддержки малого и среднего бизнеса}

\begin{tabular}{|l|l|}
\hline \multicolumn{1}{|c|}{ Направление } & \multicolumn{1}{|c|}{ Влияние } \\
\hline $\begin{array}{l}\text { Стратегические и тактические } \\
\text { приемы управления }\end{array}$ & $\begin{array}{l}\text { Объективная оценка, регулирование налогообложения, корректировка } \\
\text { нормативных правовых актов при дополнительной нагрузке, введение } \\
\text { механизма гармонизации развития бизнеса, стабильность условий на пер- } \\
\text { спективу }\end{array}$ \\
\hline Аналитическое направление & $\begin{array}{l}\text { Разработка и внедрение системы анализа развития и эффективности при- } \\
\text { меняемых мер }\end{array}$ \\
\hline Финансовое & $\begin{array}{l}\text { Для достижения мультипликативного эффекта использовать микрофинан- } \\
\text { сирование, факторинг, лизинг }\end{array}$ \\
\hline Административное & Сокращение барьеров при оптимизации правовой базы \\
\hline Инфраструктурное & $\begin{array}{l}\text { Активное развитие среды, условий инфраструктурной системы для под- } \\
\text { держки в первую очередь малого и среднего бизнеса }\end{array}$ \\
\hline Государственное & $\begin{array}{l}\text { Формирование эффективной системы государственных закупок и системы } \\
\text { закупок субъектов естественных монополий и компаний с государствен- } \\
\text { ным участием для расширения мер поддержки экспортно ориентирован- } \\
\text { ных субъектов малого бизнеса }\end{array}$ \\
\hline $\begin{array}{l}\text { Активизирующее } \\
\text { и стимулирующее }\end{array}$ & $\begin{array}{l}\text { Активная пропаганда, информирование населения о преимуществах и под- } \\
\text { держке бизнеса, о роли предпринимателя в экономике страны для повыше- } \\
\text { ния уровня занятости в этой сфере }\end{array}$ \\
\hline
\end{tabular}


Итак, предпринимательство, а в особенности - малый и средний бизнес является основой устойчивого развития любого государства в условиях рыночной экономики, поэтому важно, несмотря на сохраняющуюся геополитическую и социально-экономическую нестабильность, найти пути повышения эффективности развития и конкурентоспособности предпринимательских структур. Сдерживающие условия, негативно влияющие на предпринимательскую среду, связаны со значительной долей государствен- ного сектора в экономике, высокой налоговой нагрузкой, отсутствием системы комплексного сопровождения начинающих предпринимателей, ограниченной доступностью инвестиций, недостаточной информационной, психологической и научной поддержкой субъектов малой и средней предпринимательской деятельности, а также несовершенством и противоречивостью правовых актов, несбалансированной и некорректной (в коррупционном контексте) работой контролирующих и инспектирующих органов.

\section{Библиографический список}

1. Белова Л.В., Вишневер В.Я., Ермолаев К.Н., Коновалова М.Е., Кузьмина О.Ю., Кусков В.М., Левченко Л.В., Михайлов А.М., Недорезова Е.С., Петров Н.А., Саломатина С. Ю., Хансевяров Р. И. Учебник / Самара, 2019.Современные проблемы экономической науки (системный подход)

2. Быковская Ю.В., Иванова Л.Н., Сафохина Е.А. Малое и среднее предпринимательство в современной россии: состояние, проблемы и направления развития // Вестник евразийской науки. 2018. Т. 10. № 5. С. 6.

3. Коновалова М.Е., Кузьмина О.Ю., Михайлов А.М., Саломатина С.Ю. // Предпринимательство в системе факторов производства. Вопросы экономики и права. 2017. № 106. С. 33-36.

4. оновалова М.Е., Михайлов А.М., Кузьмина О.Ю. // Прогнозирование развития фондовых рынков в условиях становления цифровой экономики // Вестник Самарского государственного экономического университета. 2018. № 11 (169). С. 13- -19.

5. Латышенко Е.П. Перспективные направления и формы развития предпринимательства в новой экономической нормальности // Евразийское Научное Объединение. 2017. Т. 2. № 6 (28). С. 128-131.

6. Маннаков Т.В., Михайлов А.М. Формирование институтов предприятий малого бизнеса / Проблемы совершенствования организации производства и управления промышленными предприятиями: Межвузовский сборник научных трудов. 2011. № 2. С. 94-101.

7. Поляков Д. М. Государственное регулирование развития малого и среднего предпринимательства в России // Центральный научный вестник. 2018. Т. 3. № 4s (45s). С. 41.

8. Посохова А.В. Психологические особенности неконкурентоспособных предпринимателей // Власть. 2016. № 5 . С. $129-134$.

9. Тоноян А. О. Проблемы предпринимательской деятельности в России // Бенефициар. 2017. № 15. С. 11-15.

10. Единый реестр субъектов MCП. URL: https://ofd.nalog.ru/statistics.html

11. РБК. Путин рассказал о желании регионов “порадеть своим фирмёшкам”. URL: ttps://www.rbc.ru/economics /05/04/2018/5ac602c69a79479a7df1b3bb

12. Ведомости. Государство и госкомпании контролируют 70\% российской экономики. URL: https://www. vedomosti.ru/economics/articles/2016/09/29/658959-goskompanii-kontroliruyut-ekonomiki

13. ФАС. Унитарные предприятия - “теневой сектор” экономики. URL: https://fas.gov.ru/news/27023

14. Проект Федерального закона N554026-7 “О внесении изменений в отдельные законодательные акты Российской Федерации (в части установления запрета на создание и осуществление деятельности унитарных предприятий)”. URL: http://www.consultant.ru/cons/cgi/online.cgi?req=doc;base=PRJ; $\mathrm{n}=176173 \# 02641117301617242$

15. Правительство России. Комиссия по законопроектной деятельности одобрила с учётом состоявшегося обсуждения законопроект об изменениях в порядке создания и реорганизации государственных и муниципальных унитарных предприятий. URL: http://government.ru/activities/selection/302/34000/ 